\title{
KEWENANGAN MAHKAMAH KEHORMATAN DEWAN TERHADAP PENGHENTIAN JABATAN KETUA DEWAN DALAM SISTEM KETATANEGARAAN
}

\author{
Asip Suyadi, SH., M.H. \\ Fakultas Hukum Universitas Pamulang \\ asipsuyadi25@gmail.com
}

\begin{abstract}
In the 1945 Constitution explicitly and clearly the principle of equality before the law contained in Article 27 paragraph (1) states that all citizens are at the same time in law and government and are obliged to uphold the law and government; and Article 28D paragraph (1) states that everyone has the right to the recognition, guarantee, protection and fair legal certainty and equal treatment before the law. As a Board of Honor Court (MKD) that functions as a board of ethics enforcement agency, it must be based on applicable laws and regulations. Based on this, the purpose of this study is to study and analyze the authority of MKD based on the Law on the People's Consultative Assembly, the House of Representatives, the Regional Representative Council, and the Regional People's Representative Council to terminate the position of chairperson of the constitutional system. This research is descriptive analytical, with a normative juridical approach. MKD as a means of completing the board is permanent and has the authority to maintain the dignity of state organs that present people's sovereignty. $M K$ Decision Number 73 / PUU-IX / 2011 as a manifestation of judicial power. MKD power is limited by judicial power.
\end{abstract}

Keywords: Constitution, Authority, Board of Honor Court (MKD), Termination of Position of Chairperson of the Board.

\begin{abstract}
ABSTRAK
Dalam UUD Tahun 1945 secara tegas dan jelas prinsip persamaan di hadapan hukum tercantum dalam Pasal 27 ayat (1) menyatakan bahwa segala warga negara bersamaan kedudukannya di dalam hukum dan pemerintahan dan wajib menjunjung hukum dan pemerintahan; dan Pasal 28D ayat (1) menyatakan bahwa setiap orang berhak atas pengakuan, jaminan, perlindungan, dan kepastian hukum yang adil serta perlakuan yang sama di hadapan hukum. Sebagai Mahkamah Kehormatan Dewan (MKD) yang berfungsi sebagai lembaga penegakan etik anggota dewan, maka harus berdasarkan peraturan perundang-undangan yang berlaku. Berdasarkan hal tersebut, tujuan penelitian ini adalah untuk mengkaji dan menganalisis mengenai kewenananga MKD berdasarkan Undang-undang tentang Majelis Permusyawaratan Rakyat, Dewan Perwakilan Rakyat, Dewan Perwakilan Daerah, dan Dewan Perwakilan Rakyat Daerah terhadap penghentian jabatan ketua dewan dalam sistem ketatanegaraan. Penelitian ini bersifat deskriptif analitis, dengan pendekatan yuridis normatif. MKD sebagai alat kelengkapan dewan bersifat tetap dan memiliki kewenangan untuk menjaga martabat organ negara yang mempresentasikan kedaulatan rakyat. Putusan MK Nomor 73/PUU-IX/2011 sebagai wujud dari kekuasaan kehakiman. Kekuasaan MKD dibatasi oleh kekuasaan kehakiman.
\end{abstract}

Kata Kunci: Konstitusi, Kewenangan, Mahkamah Kehormatan Dewan (MKD), Penghentian Jabatan Ketua Dewan. 


\section{PENDAHULUAN}

Penegasan dalam Konstitusi Negara Republik Indonesia Pasal 1 ayat (3) Undang-Undang Dasar Tahun 1945, negara Indonesia adalah negara hukum. UndangUndang Dasar Tahu 1945 dalam Pasal 28A ayat (1) sampai denga Pasal 28J ayat (2), yang memberikan jaminan dan perlindungan kepada setiap hak asasi manusia. Kewajiban untuk menghormati hak asasi manusia dan tanggung jawab negara atas tegaknya hak asasi manusia telah tertuang dalam konstitusi negara yang tercantum dalam pasal 29 ayat (2), Pasal 30 ayat (1), dan Pasal 31 ayat (1) UndangUndang Dasar Tahun 1945.Negara hukum menurut F. R. Bothlingk adalah de taat waarin de wilsvriheid van gezagsdragers is beperkt door grenzen van recht (negara, dimana kebebasan kehendak pemegang kekuasaan dibatasi oleh suatu kehendak hukum) (HR, 2014 : 21). Lebih lanjut disebutkan bahwa dalam rangka merealisasikan pembatasan pemegang kekuasaan tersebut maka diwujudkan dengan cara enerzijds in een binding van rechter administratie aan de wet, anderjizds in een begrenzing van de bevoegheden van de wetgever (disatu sisi keterikatan hakim dan pemerintah terhadap undang-undang, di sisi lain pembatasan kewenangan oleh pembuat undang-undang.

Penegasan negara Indonesia sebagai negara hukum dan bukan negara kekuasaan, Jimly Asshiddiqie menguraikan bahwa: "Penegasan negara Indonesia sebagai negara hukum di dalammnya terkandung pengertian adanya pengakuan terhadap prinsip supremasi hukum dan konstitusi, dianutnya prinsip pemisahan dan pembatasan kekuasaan menurut sistem konstitusional yang diatur dalam UUD, adanya jaminan-jaminan hak asasi manusia dalam UUD, adanya prinsip peradilan yang bebas dan tidak memihak yang menjamin persamaan setiap warga negara dalam hukum, serta menjamin keadilan bagi setiap orag termasuk terhadap penyalahgunaan wewewnang oleh pihak yang berkuasa" (Asshiddiqie, $2003: 2$ ).

Menurut A. Hamid S. Attamimi, ini berarti bahwa dalam konsep negara hukum, negara menempatkan hukum sebagai dasar kekuasaan negara dan penyelenggaraan kekuasaan tersebut dalam segala bentuknya dilakukan di bawah kekuasaan hukum (Attamimi, 1990 : 74). Franz Magnis Suseno menegaskan bahwa dalam konsep negara hukum, kekuasaan harus dijalankan atas dasar hukum yang baik dan adil (MagnisSuseno, 1994 : 295). Menurut Philipus M. Hadjon, ide rechsstaat cenderung ke arah positivisme hukum yang membawa konsekuensi bahwa hukum dibentuk secara sadar oleh bada pembentuk undang-undang (Hadjon, 1994 : 6).

Keistimewaan bagi anggota dewan banyak dikenal dalam berbagai praktek kenegaraan. Keistimewaan bagi anggota dewan sering dikenal sebagai parliamentary privileges. Pengistimewaan anggota dewan perlu diperhatikan adanya peradilan yang bebas dan tidak memihak. Polemik adanya persyaratan izin dari Mahkamah Kehormatan Dewan (MKD) merupakan itervensi pada kekuasaan kehakiman. Kenyataan bahwa suatu negara memberikan arahan berkaitan dengan pengaturan keneagaraan maka pejabat publik dan penyelenggara negara harus mampu memberikan kontribusi dalam penerapan prinsip Good Governance (Rezky, 2019: 5)

Prinsip persamaan hukum sangat jelas dituangkan dalam Pasal 27 ayat (1) UUD 1945 yang menyebutkan: "Bahwa segala warga negara bersamaan kedudukannya di dalam hukum dan 
pemerintahan dan wajib menjunjung hukum dan pemerrintahan itu dengan tidak ada kecualinya”. Pasal 28D ayat (1) UUD 1945 menyebutkan bahwa setiap orag berhak atas pengakuan, jaminan, perlindungan dan kepastian hukum yang adil serta perlakuan yang sama di hadapan hukum.

Dalam Putusan MK Nomor 73/PUUIX/2011, Mahkamah Konstitusi berpendapat bahwa adanya syarat persetujuan tertulis dari Presiden untuk melakukan penyelidikan dan penyidikan, akan menghambat percepatan proses peradilan dan secara tidak langsung mengintervensi sistem penegakan keadilan. Mahkamah Konstitusi juga berpendapat dalam putusan Mahkamah Konstitusi Nomor 6-13-20/PUU-VIII/2010 jo. Putusan Mahkamah Konstitusi Nomor 73/PUUIX/2011, bahwa tafsir kekuasaan kehakiman meliputi hal-hal yang berkaitan dengan penegakan hukum dan keadilan dalam penyelenggaraan sistem peradilan pidana.

Pengawasan perilaku anggota parlemen dapat berasal dari luar kelembagaan parlemen maupun maupun dari internal parlemen. Pengawasan eksternal bisa dilakukan oleh konstituen secara langsung maupun oleh partai politik. Sementara pengawasan dari dalam dapat dilakukan oleh sebuah lembaga yang dibentuk oleh parlemen itu sendiri yang biasa disebut dengan Badan Kehormatan (BK) atau Mahkamah Kehormatan Dewan (MKD) (Karyanti, Juni 2015 : 60).

Sebagai alat kelengkapan Dewan Perwakilan Rakyat, MKD bersifat tetap dan merupakan lembaga yag memiliki kewenangan untuk menjaga martabat parlemen sebagai organ negara yang mempresentasikan kedaulatan rakyat. Secara teoritis dampak dari adanya reformasi yang berhasil mengamandemen UUD 1945 sudah mencatat berbagai perubahan mendasar yang terjadi khususnya dalam tatanan egara (pemerintahan) (Rusnan, Desember 2017 : 365).

Berdasarkan uraian di atas maka Penulis tertarik untuk membahas dan menganalisis problem pembentukan dan kewenangan Mahkamah Kehormatan Dewan (MKD) dalam sistem ketatanegaraan yang akan dituangkan dalam judul "Kewenangan Mahkamah Kehormatan Dewan Terhadap Penghentian Jabatan Ketua Dewan Dalam Sistem Ketatanegaraan”.

\section{PERMASALAHAN}

Berdasarkan permasalahan yang diuraikan di atas maka Penulis akan menganalisis permasalahan yang ada berdasarkan analisis hukum Penulis, yang akan dipaparkan sebagai berikut: Pertama, Apa kewenangan mahkamah kehormatan dewan atas penghetian jabatan ketua dewan perwakilan daerah secara otomatis dapat menghentikan status sebagai anggota dewan? Kedua, Apa dasar hukum mahkamah kehormatan dewan dalam penghentian status jabatan ketua dewan?

\section{METODE PENELITIAN}

Jenis penelitian yang digunakan adalah penelitian normatif, penelitian ini merupakan penelitian yang ditujukan untuk menemukan dan merumuskan argumentasi hukum melalui analisis terhadap pokok masalah (Djamiati, 2005 : 3) Dalam penelitian hukum normatif, hukum dikonsepkan sebagai apa yang tertulis dalam perundang-undangan, atau hukum dikonsepkan sebagai apa yang tertulis dalam perundang-undangan atau hukum dikonsepkan sebagai norma yang merupakan patokan berperilaku manusia yang dianggap pantas (Askin, 2006 : 118). Spesifikasi penelitian ini adalah penelitian 
yang bersifat deskriptif, yaitu menggambarkan perundang-undangan yang berlaku dan dikaitkan dengan teoriteori hukum dalam praktik pelaksanaannya yang menyangkut permasalahan atau isu hukum yang diteliti (Soekanto, 1986 : 9-10).

Sumber data yang digunakan dalam penelitian ini adalah data primer dan data sekunder. Bahan hukum primer yaitu bahan yang bersumber dari peraturan perundangundangan dan dokumen hukum yang mempunyai kekuatan hukum yang mengikat karena dibuat dan diumumkan secara resmi oleh pembentuk hukum Negara (Soekanto S. , 2002 : 52). Bahan hukum sekunder yaitu bahan yang memberi penjelasan terhadap bahan hukum primer, misalnya: rancangan undang-undang, hasilhasil penelitian, hasil karya pakar hukum, dan sebagainya (Ali, 2013 : 23). Teknik pengumpulan bahan hukum dalam penelitian ini dilakukan melalui studi kepustakaan (library Research). Dalam studi kepustakaan ini lebih menekankan pada teknik penelusuran dokumen, yakni bahan-bahan tertulis yang berisi informasi tentang phenomena objek yang diteliti baik dokumen primer dan sekunder. Bahan hukum yang telah terkumpul diidentifikasi dan kemudian disusun secara sistematis.

\section{PEMBAHASAN}

Asas kedaulatan rakyat yang dikenal sebagai asas atau dasar demokrasi, hal ini juga dikenal dalam konstitusi di banyak negara. Adapun demikian, setiap negara mempunyai sistem atau mekanisme tersendiri untuk melaksanakan asas atau dasar tersebut. Dari negara yang sistem pemerintahannya menganut sistem parlementer akan berbeda dengan negara yang menganut sistem pemerintahan presidensial (Asshiddiqie, Gagasan Kedaulatan Rakyat Dalam Konstitusi dan Pelaksanaannya di Indonesia, 1994 : 87).
Dalam kajian tentang pelaksanaan asas kedaulata rakyat, dalam sistem UUD 1945, rujukan pertama adalah hukum positif, yaitu ketentuan yang terdap[at dalam UUD 1945. Dengan memperhatikan ketentuan yang terdapat dalam UUD 1945 , asas kedaulata rakyat atau demokrasi dapat dilakukan dalam dua tahap: Petama, langsung oleh rakyat kemudian dilanjutkan dengan tahap Kedua, yaitu tahap tidak langsung yang dilakukan oleh lembagalembaga perwakilan.

Semua kewenangan yang dimiliki oleh lembaga-lembaga perwakilan negara tersebut diatur dalam konstitusi negara Republik Indonesia, yaitu UUD 1945. Berdasarkan kewenangan yang terdapat dalam Undang-Undang Dasar, maka dibentuk kewenangan-kewenangan lainnya melalui pembentukan Undang-undang yang diamanatkan konstitusi. Pelaksanaan tugas oleh setiap pejabat pemerintahan dilandasi wewenang yang sah berdasarkan peraturan perundang-undangan. Untuk menghindari abuse of power, semua kekuasaan harus dibatasi oleh hukum atau peraturan perundang-undangan.

Dalam setiap penyelenggaraan negara dan pemerintahan haruslah didasarkan pada suatu proses yakni demokrasi. Dalam konsep negara demokrasi, mengenal adanya lembaga perwakilan. Di Indonesia sendiri lembaga perwakilan rakyat di sebut sebagai lembaga parlemen. Salah satu lembaga parlemen di Indonesia adalah Dewan Perwakilan Rakyat (DPR). Dalam rangka melaksanakan fungsi dan tugasnya DPR memiliki beberapa unit kerja yang biasa disebut dengan alat-alat kelengkapan DPR, salah satu alat kelengkapan DPR yang sangat penting adalah Mahkamah Kehormatan Dewan (MKD). MKD sebagai alat kelengkapan DPR yang bersifat tetap, dibentuk dengan tujuan untuk menjaga serta menegakkan 
kehormatan dan keluhuran martabat DPR. Seiring dengan perkembangannya sejak adanya UU No. 2 Tahun 2018 (UU MD3), Kewenangan MKD mengalami banyak perubahan terlihat jelas pada Pasal 122 yang menyatakan bahwa," $M K D$ dapat mengambil langkah hukum/langkah lain terhadap orang ataupun badang hukum yang merendahkan kehormatan DPR serta anggota $\mathrm{DPR}^{\text {ceee }}$, serta Kewenangan MKD yang tertuang dalam Pasal 245 yang menyatakan bahwa „Pemanggilan dan permintaan keterangan kepada anggota DPR sehubungan dengan terjadinya tindak pidana yang tidak sehubungan dengan pelaksanaan tugas sebagaimana dimaksud dalam Pasal 224 harus mendapatkan persetujuan tertulis dari Presiden setelah mendapat pertimbangan dari Mahkamah Kehormatan Dewan. Dengan dikeluarkannya UU MD3 tersebut, masyarakat menilai bahwa kewenangan MKD yang tertuang dalam UU MD3 dapat mencederai konstitusi dan merupakan suatu bentuk nyata kemunduran demokrasi yang dilakukan oleh DPR. Berdasarkan uraian latar belakang diatas, muncul isu hukum yakni Bagaimana bentuk Kewenangan Mahkamah Kehormatan Dewan menurut Undang-undang Nomor 2 Tahun 2018 dan Apakah Kewenangan Mahkamah Kehormatan Dewan yang diatur dalam Undang-undang Nomor 2 Tahun 2018 sesuai dengan Konsep Negara Demokrasi. Tujuan penulisan skripsi ini terdiri atas tujuan umum dan tujuan khusus. Tujuan umum skripsi ini adalah melengkapi dan memenuhi tugas pokok akademis untuk meraih gelar Sarjana Hukum pada Fakultas Hukum Universitas Jember dan untuk menambah ilmu pengetahuan serta mengembangkan pemikiran bagi masyarakat luas. Tujuan khusus penulisan skripsi ini adalah Mengkaji Bentuk Kewenangan Mahkamah
Kehormatan Dewan tehadap Demokrasi di Indonesia. Tipe penelitian yang digunakan dalam skripsi adalah penelitian yuridis normative (legal approach). Penulis menggunakan pendekatan Perundangundangan (statute approach) serta pendekatan historis (historical approach).

Mahkamah Kehormatan Dewan (MKD) merupaka alat kelengkapan DPR yang bersifat tetap yang pembentukannya dilakukan oleh DPR RI periode 2014-2019 sebagai perbaikan dari Badan Kehormatan pada periode sebelumnya. MKD bertujuan menjaga serta menegakkan kehormatan dan citra DPR. Sebagaimana tertuang dalam Pasal 122 Undang-Undang Nomor 2 Tahun 2018 tentang Perubahan Kedua Atas Undang-Undang Nomor 17 Tahun 2014 tentang MPR, DPR, DPD dan DPRD.

Sistem penegakan kode etik DPR RI dilakukan MKD sebagaimana yang terdapat dalam ketentua Pasal 19 Peraturan DPR RI Nomor 1 Tahun 2015 tentang Kode Etik. Penegakan dilakukan dengan 2 (dua) sistem, yaitu sistem pencegahan dan sistem penindakan. Pasal 15 Peraturan Dewan Perwakilan Rakyat Republik Indonesia Nomor 2 Tahun 2015 tentang Tata Beracara MKD DPR RI, sebelum menjatuhi sanksi kepada pelanggar, dilakukan rapat MKD untuk menentukan apakah perkara tersebut akan ditindaklanjuti atau diberhentikan. Apabila perkara tersebut akan ditindaklanjuti maka diadakan acara sidang yang dimana pengadu, teradu, saksi dan/atau ahli hadir. Sidang MKD bersifat tertutup, kecuali apabila dinyatakan terbuka oleh sidang MKD, karena pimpinan dan anggota MKD diwajibkan menjaga kerahasiaan informasi yang diperoleh dalam sidang MKD.

Perubahan UUD Negara Republik Indonesia 1945 telah menempatkan DPR sebagai lembaga legislasi yang sebelumnya berada di tangan presiden. Denga demikian 
DPR memiliki fungsi politik yang sangat strategis, yaitu sebagai lembaga penentu arah kebijakan kenegaraan (Titik, 2010 : 192). Dalam Pasal 119 ayat (1) dan ayat (2) Undang-Undang Nomor 17 Tahun 2014 tentang MPR, DPR, DPD, DPRD, menjelaskan bahwa MKD dibentuk oleh DPR dan merupakan alat kelengkapan DPR yang bersifat tetap, yang bertujuan menjaga kehormatan DPR. Dasar hukum Mahkamah Kehormatan Dewan (MKD) dalam penghentian status jabatan ketua dewan diatur dalam Peraturan DPR RI Nomor 2 Tahun 2015 tentang Tata Beracara MKD DPR RI. Aggota sidang MKD terdiri dari kelompok kerja dan/atau tim panel, tim panel berasal dari MKD dan masyarakat, dari anggota MKD dipilih berdasarkan musyawarah mufakat atau voting terbanyak sedangkan dari masyarakat bakal anggota pleno harus yang memiliki integritas yang mewakili tokoh masyarakat, dan/atau praktisi hukum, diseleksi dan ditetapkan dalam rapat pleno MKD. (Peraturan DPR RI Nomor 2 Tahun 2015 tetang Tata Beracara MKD DPR RI).

Pasal 46 ayat (1) Peraturan DPR RI Nomor 2 Tahun 2015 tentang Tata Beracara MKD DPR RI, menyatakan bahwa anggota panel memiliki tugas yang perlu dilakukan, seperti: melaksanakan acara pemeriksaan, membuat resume mengenai pemeriksaan yang dilakukan, serta membuat laporan panel yang berisi catatan rapat, risalah, pemeriksaan, dan berita acara pemeriksaan. Pasal 46 ayat (2) Peraturan DPR RI Nomor 2 Tahun 2015 tentang Tata Beracara MKD DPR RI, dalam melaksanakan tugasnya panel juga memiliki wewenang guna membantu pelaksanaan tugas, seperti: memanggil dan meminta keterangan para pihak, saksi, dan ahli. Untuk meminta keterangan panel berwenang mengambil sumpah dalam acara pemeriksaan, serta memeriksa dan mengesahkan alat bukti dan barang bukti yang terdapat dalam acara pemeriksaan dan panel juga dapat memita alat bukti dan barang bukti lainnya.

Pasal 63 Peraturan DPR RI Nomor 2 Tahun 2015 tentang Tata Beracara MKD DPR RI, menyatakan bahwa: Jenis sanksi yang diberikan kepada Pimpinan AKD dan Anggota yang dinyatakan bersalah berdasarkan putusan MKD berupa: a. Sanksi ringan dengan teguran lisan atau teguran tertulis; b. Sanksi sedang dengan pemindahan keanggotaan pada Alat Kelengkapan DPR atau pemberhentian dari jabatan Pimpinan DPR atau Pimpinan Alat Kelengkapan DPR dan diumumkan kepada publik; atau c. Sanksi berat dengan pemberhentian sementara paling singkat 3 (tiga) bulan atau pemberhentian sebagai Anggota. Untuk memberikan saksi kepada pelanggar, MKD melakukan prosedur sesuai dengan sistem yag telah ditentukan berdasarkan undang-undang dan peraturan yang berlaku.

\section{PENUTUP \\ Kesimpulan}

Pertama, dasar hukum Mahkamah Kehormatan Dewa (MKD) atas penghentian Ketua Dewan diatur dalam Peraturan DPR RI Nomor 2 Tahun 2015 tentang Tata Beracara MKD DPR RI. Kedua, Peraturan DPR RI Nomor 2 Tahun 2015 tentang Tata Beracara MKD DPR RI sebagai dasar hukum dalam pengendalian anggota DPR dalam bekerja dan bertigkah laku. Ketiga, MKD juga berwenang atas pelanggaran kode etik dan tata tertib yang dilakukan oleh anggota DPR yang diatur dalam Undang-Undang Nomor 2 Tahun 2018 tentang Perubahan Kedua Atas UndangUndang Nomor 17 Tahun 2014 tentang MPR, DPR, DPD, dan DPRD. 


\section{Saran:}

Pertama, MKD harus mengoktimalkan fungsi dan kewenanga secara independen berdasarkan Peraturan DPR RI Nomor 2 Tahun 2015 tentang Tata Beracara MKD DPR RI dalam menjaga kehormatan DPR RI. Kedua, harus professional dan independen berdasarkan Undang-Undang Nomor 2 Tahun 2018 tentang Perubahan Kedua Atas UndangUndang Nomor 17 Tahun 2014 tentang MPR, DPR, DPD, dan DPRD dalam menegakkan kode etik anggota DPR RI. Ketiga, masyarakat turut berperan aktif dalam melakukan pengawasan terhadap kinerja dan tingkah laku aggota DPR RI agar sesuai dengan mandat dan kedaulatan rakyat yang berdasarkan konstitusi.

\section{DAFTAR PUSTAKA}

A. Hamid S. Attamimi, "Peranan Keputusa Presiden Republik Indonesia dalam Penyelenggaraan Pemerintahan Negara", Disertasi, Pascasarjana Uiversitas Indonesia, 1990.

Amiruddin dan Zainal Askin, "Pengantar Metode Penelitian Hukum", RajaGrafindo Persada, Jakarta, 2006.

Dunny, Ismail, "Mencari Keadilan", Ghalia Indonesia, Jakarta, 1982.

Frans Magnis-Suseno, "Etika Politik: Prinsip-prinsip Dasar Kenegaraan Modern", Gramedia Pustaka Utama, Jakarta, 1994.

Jimly Asshiddiqie, "Gagasan Kedaulatan Rakyat Dalam Konstitusi dan Pelaksanaannya di Indonesia”, PT. Ichtiar Baru Van Hoeven, Jakarta, 1994.
Jimly Asshiddiqie, "Struktur Ketatanegaraan Indonesia Setelah Perubahan Keempat UUD 1945", Makalah dalam Simposium Nasional BPHN Departemen Hukum dan HAM di Denpasar, 1418 Juli 2003.

Kusuma, RMAB, "Lahirnya Undang-Undag Dasar 1945”, Badan Penerbit FHUI, Jakarta, 2004.

MP, H. Muhamad Rezky Pahlawan. "TINJAUAN TEORITIS KEPUTUSAN PEJABAT NEGARA DIKAITKAN DENGAN SISTEM HUKUM NEGARA INDONESIA." RECHTSREGEL Jurnal Ilmu Hukum 1.2 (2019).

Philipus M. Hadjon, "Ide Negara Hukum Dalam Sistem Ketatanegaraan Republik Indonesia”, Makalah pada Simposium Politik, Hak Asasi Manusia, dan Pembangunan, dalam Rangka Dies Natalis Universitas Airlangga, Surabaya, 1994.

Philipus M. Hajdon dan Tatiek Sri Djamiati, "Argumentasi Hukum", Gadjah Mada University Press, Yogyakarta, 2005 .

Ridwan HR, "Hukum Administrasi Negara", Rajawali Pers, Jakarta, 2014.

Rusnan, "Kedudukan Mahkamah Kehormatan Dewan Dalam Sistem Parlemen Di Indonesia”, Jurnal IUS, Volume V, Nomor 3, Desember 2017. 
Soejono Soekanto, "Pengantar Penelitian Hukum”, Universitas Indonesia UIPerss, Jakarta, 2002.

Soerjono Soekanto, "Pengantar Penelitian Hukum”, UI Press, Jakarta, 1986.

Sri Karyanti, "Rekonstruksi Kelembagaan Penegakan Etika Parlemen", Jurnal Etika dan Pemilu, volume 1, Nomor 1, Juni 2015.

Titik Triwulan Titik, "Konstruksi Hukum Tata Negara Pasca Amandemen UUD 1945”, KencanaPrenada Media Group, Jakarta, 2010.

Zainuddin Ali, "Metode Penelitian Hukum", Sinar Grafika, Jakarta, 2013. 